\title{
Analysis of Empowerment through Decision Making of Women in Madurai District of Tamil Nadu - A Study
}

Selvaraj Narayanan*

Department of Commerce, Saraswathi Narayanan College, Madurai, Tamilnadu, India

\begin{abstract}
Poor people, especially poor women have traditionally not been recognized as credit-worthy or able to save and thus they are not perceived to be a profitable market of credit. This forces them to fall in the vicious cycle of everlasting high interest and high collateral loan from money lenders. The sine quo none of any anti-poverty strategy is the irrepressible desire and innate capacity of the poor to uplift their conditions. Therefore, the need comes for innovative credit delivery systems which deviate from formal collateral oriented lending institutions to informal structures. It has been felt all over the world today that micro-finance performances can simultaneously help in alleviation of poverty and empowering women. Many micro credit institutions/programmes (MFI/Ps) have targeted women who live in households having little or no assets. These MFI/Ps have significantly increased women's security, autonomy, selfconfidence and status within the households by providing opportunities for self-employment. Micro credit managed and utilized by women borrowers themselves has the greatest impact on poverty reduction.
\end{abstract}

Keywords: Empowerment; Micro-credit; Decision-Making; Women and Indices

\section{Introduction}

The essential features of the modern micro-finance concept include delivery of credit and then facilities in a convenient and user-friendly way, quick disbursement of small and short loans, maintenance of high recovery rates through pressure, incentives of access to larger loans immediately following successful repayment of the first loan, encouraging and accepting savings through group decisions and peer support and linking credit with savings. The new paradigm emphasizes financial intermediation with self-sustainability of institutions and qualitative and quantitative outreach to the poor.

Poor people, especially poor women have traditionally not been recognized as credit-worthy or able to save and thus they are not perceived to be a profitable market of credit. This forces them to fall in the vicious cycle of everlasting high interest and high collateral loan from money lenders. The sine quo none of any anti-poverty strategy is the irrepressible desire and innate capacity of the poor to uplift their conditions. Therefore, the need comes for innovative credit delivery systems which deviate from formal collateral oriented lending institutions to informal structures. It has been felt all over the world today that micro-finance performances can simultaneously help in alleviation of poverty and empowering women [1-3].

\section{Micro Credit and Women}

Many micro credit institutions/programmes (MFI/Ps) have targeted women who live in households having little or no assets. This MFI/Ps has significantly increased women's security, autonomy, self-confidence and status within the households by providing opportunities for self-employment. Micro credit managed and utilized by women borrowers themselves has the greatest impact on poverty reduction. Over a decade of banking with the Grameen Bank, women as loan managers are less likely to remain poor, as most of them (eight out of ten) will be out of poverty after a few loan cycles. Partnership of women with their spouses or other adult household members in loan utilization and management, on the other hand, is also more likely to move them out of poverty, with a probability of six in ten $[4,5]$.

\section{Objectives of the Study}

To evaluate the decision making power on women and to offer suitable suggestions based on the findings.

\section{Period of Study}

The present study is based on the primary. The primary data have been collected from the respondents directly for the period of study is impounded to one year. (i.e., 2015-2016)

\section{Analytical Framework}

The empowerment of women in the present study has been measured in terms of their decision making capacity which has been classified on the basis of:

a) Self,

b) Myself more than husband/family member,

c) Both Equal,

d) Husband/family member more than myself and

e) Husband/family member.

These five aspects are applicable for seven variables which are identified for measuring the decision making power of women. The identified variables are:

i) Preparation of the family budget,

ii) Education of children,

*Corresponding author: Selvaraj N, Assistant Professor of Commerce, Saraswath Narayanan College, Madurai, Tamilnadu, India, Tel: 09843727975; E-mail: selvaraj_narayanan@yahoo.com

Received July 15, 2016; Accepted August 19, 2016; Published August 27, 2016

Citation: Narayanan S (2016) Analysis of Empowerment through Decision Making of Women in Madurai District of Tamil Nadu - A Study. Intel Prop Rights. 4: 161. doi: 10.4172/2375-4516.1000161

Copyright: @ 2016 Narayanan S. This is an open-access article distributed under the terms of the Creative Commons Attribution License, which permits unrestricted use, distribution, and reproduction in any medium, provided the original author and source are credited. 
iii) Health and medicine,

iv) Leisure activities,

v) Purchase of home appliances,

vi) Giving away gifts to others and

vii) Personal needs.

The responses have been obtained from the sample women work beneficiaries in five aspects for each variable. The responses observed for each variable have been scored. To secure the total empowerment score of a women beneficiary, five points are given for 'self', four points for 'myself more than husband/family member', three points are given for 'both equal', two points for 'husband/family member more than myself and one point for 'husband/family member' responses. Thus, the total empowerment score of a respondent is obtained by adding up the scores of all seven variables [6].

One way ANOVA test was carried out to examine whether women beneficiaries in different sectors have caused significant variation in empowerment.

The level of empowerment has been classified into three categories, namely low level, medium level, and high level for analytical purposes. The level of empowerment has been said to be high when the score values are greater than or equal arithmetic mean plus standard deviation and if the score values are less than or equal arithmetic mean minus standard deviation then it has been classified as low level empowerment, and if the score value is between arithmetic mean plus standard deviation, and arithmetic mean minus standard deviation then it has been classified as medium level empowerment. Arithmetic mean and standard deviations are calculated from the score values.

In order to examine the relationship between the level of empowerment and economic factors, the chi-square test has been applied. It is calculated by adopting the following formula.

$$
\text { Chi }- \text { square }=\sum \frac{(\mathrm{O}-\mathrm{E})^{2}}{\mathrm{E}}
$$

With (r-1) (c-1) degrees of freedom.

Where,

\section{O: Observed frequency}

E: Expected frequency

$$
\mathrm{E}=\frac{\text { Row total X Column total }}{\text { Grand Total }}
$$

C: Number of rows in a contingency table

R: Number of column in a contingency table
' $t$ ' test has been used to examine the significance in change of prepost credit periods.

In order to access the contribution of independent variables to women empowerment, step wise multiple regression analysis was carried out.

In this section, an attempt has been made to analyze the decision making power enjoyed by women participants/beneficiaries on the variables namely i) Preparation of the family budget, ii) Education of children, iii) Health and medicine, iv) Leisure activities, v) Purchase of home appliances, vi)Giving away gifts to others and vii) Personal needs.

\section{Preparation of the Family Budget}

Family budget here refers to the various items to be purchased daily and the amount of money to be spent on each item, variation in the terms of consumption and the like. The decision making of women respondents on preparation of the family budget is presented in Table 1.

It is evident from Table 1 that nearly 40.74 per cent of the respondent in manufacturing sector activity, 37.25 per cent of the respondents in service sector activity, 30.77 per cent of the respondents in trading sector activity take independent decision relating to the family budget. Independent decision making was found less in manufacturing sector activity, when compared to, service and trading sectors activity. Joint decisions were taken by 27.27 per cent of the respondents in the case of manufacturing sector activity, while it was 18.80 percent in trading sector activity. Husband/family members alone taking decision was 10.92 per cent in manufacturing sector, 11.77 per cent in service sector, 16.24 per cent in trading sector. Thus, it is inferred from the analysis that majority of the respondents could take decision independently relating to family budget in all the three sectors.

\section{Education of the Children}

Education is a crucial factor which determines the future of a person. Decision making concerning the education of the children is an important factor for measuring the empowerment of women. Table 2 clearly exhibits the decision making power of the women respondents related to education of the children.

Decision making regarding the education of children here refers to the kind of schools in which they intend to enroll their children to study and so on (Table 2).

From the Table 2, it is learnt that nearly 7.41 per cent of the respondent in manufacturing sector activity, 34.31 per cent of the respondents in service sector activity, 7.69 per cent of the respondents in trading sector activity, take independent decision relating to the

\begin{tabular}{|c|c|c|c|c|c|c|c|c|}
\hline \multirow[t]{2}{*}{ Final decision Taken } & \multicolumn{2}{|c|}{ Manufacturing Sector } & \multicolumn{2}{|c|}{ Service Sector } & \multicolumn{2}{|c|}{ Trading Sector } & \multicolumn{2}{|c|}{ Overall Total Score } \\
\hline & No. of Res. & Score & No. of Res. & Score & No. of Res. & Score & No. of Res. & Score \\
\hline Myself & $33[40.74]$ & 112 & $38[37.25]$ & 132 & $36[30.77]$ & 122 & 107 [35.67] & 366 \\
\hline Myself more than husband & $5[6.17]$ & 18 & $11[10.78]$ & 30 & 15 [12.82] & 43 & 31 [10.33] & 91 \\
\hline Both & $22[27.16]$ & 47 & 26 [25.49] & 56 & $22[18.80]$ & 48 & 70 [23.33] & 151 \\
\hline $\begin{array}{l}\text { Husband/Family member more } \\
\text { than myself }\end{array}$ & $13[16.05]$ & 19 & $15[14.71]$ & 21 & $25[21.37]$ & 37 & $53[17.67]$ & 77 \\
\hline Husband/Family members & $8[9.88]$ & 8 & $12[11.77]$ & 10 & 19 [16.24] & 16 & $16[13.00]$ & 34 \\
\hline Total & 55 [100] & 204 & $102[100]$ & 249 & $117[100]$ & 266 & 300 [100] & 719 \\
\hline
\end{tabular}
children's education in their family. The percentage of respondents who

Source: Survey data.

Note: Figures in brackets are percentage to the total.

Table 1: Decision making on preparation of the family budget. 
Citation: Narayanan S (2016) Analysis of Empowerment through Decision Making of Women in Madurai District of Tamil Nadu - A Study. Intel Prop Rights. 4: 161. doi: 10.4172/2375-4516.1000161

Page 3 of 5

jointly decide about the education of their children in manufacturing sector, service sector and trading sector are 40.74 per cent, 11.76 per cent and 32.48 per cent respectively. The percentage of husband/ family members decision taking in this respect was 3.70, 27.46 and 22.23 per cent in the case of manufacturing sector, trading sector and service sector respectively. Thus, it is understood on this basis of the score value that the women in both areas decide the education of their children independently (Table 3 ).

\section{Health and Medicine}

Women have major responsibility to look after the health of their family members. Table 3 furnishes the details of decision making of women on health and medicine.

It is inferred from the Table 3 that 40.74 per cent of the respondents in manufacturing sector activity, 32.35 per cent of the respondents in service sector activity and 23.08 per cent of the respondents in trading sector activity take independent decision regarding health and medicine. Independent decision making was found more in manufacturing sector when compared to others sectors. Joint decision was found high, about 35.29 per cent in service sector and 47.01 per cent in trading sector activity. Husband/family members' decision making was 30.86 per cent in manufacturing sector activity, 3.93 per cent in service and 2.56 per cent in trading sector activity. Thus it is clear from the total score that majority of the respondents take decision independently regarding their health and medicine in service sector.

\section{Leisure Time Activities}

Leisure time activities are essential for the health and happiness of a family. It is one of the vital factors in the life span. The decision making on the leisure activities here refers to the recreational activities, that is regarding the visit to the cinema theatres, watching televisions, chatting, making some painting, handicrafts, stitching, visiting the relatives/friends' houses and so on. Table 4 depicts the decision making among the women respondents regarding the leisure time activities (Table 4).

From the Table 4 it is evident that 7.41 per cent in manufacturing, 20.59 per cent in service, and 10.26 per cent in trading sectors take decision independently regarding leisure activity in their family. When agricultural sector is compared with manufacturing sector, independent decision making was found more in manufacturing sector. The percentage of the respondents who decide jointly the leisure activity in manufacturing sector and trading sector are 32.10 per cent and 32.48 per cent respectively. The percentage of husband/family members' decision making in this regard is 22.22 and 16.24 in the case

\begin{tabular}{|c|c|c|c|c|c|c|c|c|}
\hline \multirow[t]{2}{*}{ Final decision Taken } & \multicolumn{2}{|c|}{ Manufacturing Sector } & \multicolumn{2}{|c|}{ Service Sector } & \multicolumn{2}{|c|}{ Trading Sector } & \multicolumn{2}{|c|}{ Overall Total Score } \\
\hline & No. of Res. & Score & No. of Res. & Score & No. of Res. & Score & No. of Res. & Score \\
\hline Self & $6[7.41]$ & 22 & $35[34.31]$ & 124 & $9[7.69]$ & 33 & $50[16.67]$ & 179 \\
\hline Myself more than husband & 21 [25.93] & 59 & $8[7.84]$ & 23 & $24[20.51]$ & 67 & $53[17.67]$ & 149 \\
\hline Both & $33[40.74]$ & 68 & $12[11.76]$ & 27 & 38 [32.48] & 81 & 83 [27.66] & 176 \\
\hline $\begin{array}{l}\text { Husband/Family member more } \\
\text { than myself }\end{array}$ & 18 [22.22] & 26 & 19 [18.63] & 29 & 20 [17.09] & 29 & $57[19.00]$ & 84 \\
\hline Husband/Family members & $3[3.70]$ & 4 & $28[27.45]$ & 22 & 26 [22.23] & 18 & $57[19.00]$ & 44 \\
\hline Total & 81 [100] & 179 & $102[100]$ & 225 & $117[100]$ & 228 & $300[100]$ & 632 \\
\hline
\end{tabular}

Source: Survey data

Note: Figures in brackets are percentage to the total.

Table 2: Decision making on education of children.

\begin{tabular}{|c|c|c|c|c|c|c|c|c|}
\hline \multirow[t]{2}{*}{ Final decision Taken } & \multicolumn{2}{|c|}{ Manufacturing Sector } & \multicolumn{2}{|c|}{ Service Sector } & \multicolumn{2}{|c|}{ Trading Sector } & \multicolumn{2}{|c|}{ Overall Total Score } \\
\hline & No. of Res. & Score & No. of Res. & Score & No. of Res. & Score & No. of Res. & Score \\
\hline Self & $31[40.74]$ & 113 & 33 [32.35] & 117 & 27 [23.08] & 97 & 91 [30.33] & 327 \\
\hline Myself more than husband & $6[7.41]$ & 14 & 21 [20.59] & 58 & $24[20.51]$ & 66 & $51[17.00]$ & 138 \\
\hline Both & 7 [9.88] & 17 & 36 [35.29] & 77 & $55[47.01]$ & 117 & 98 [32.67] & 211 \\
\hline $\begin{array}{l}\text { Husband/Family member more } \\
\text { than myself }\end{array}$ & $12[14.81]$ & 19 & $8[7.84]$ & 12 & $8[6.84]$ & 12 & 28 [9.33] & 43 \\
\hline Husband/Family members & $25[30.86]$ & 19 & 4 [3.93] & 5 & $3[2.56]$ & 4 & $32[10.67]$ & 28 \\
\hline Total & $81[100]$ & 182 & $102[100]$ & 269 & $117[100]$ & 296 & $300[100]$ & 747 \\
\hline
\end{tabular}

Source: Survey data

Note: Figures in brackets are percentage to the total.

Table 3: Decision making on health and medicine.

\begin{tabular}{|c|c|c|c|c|c|c|c|c|}
\hline \multirow[t]{2}{*}{ Final decision Taken } & \multicolumn{2}{|c|}{ Manufacturing Sector } & \multicolumn{2}{|c|}{ Service Sector } & \multicolumn{2}{|c|}{ Trading Sector } & \multicolumn{2}{|c|}{ Overall Total Score } \\
\hline & No. of Res. & Score & No. of Res. & Score & No. of Res. & Score & No. of Res. & Score \\
\hline Self & $6[7.41]$ & 23 & $21[20.59]$ & 73 & $12[10.26]$ & 42 & $39[13.00]$ & 138 \\
\hline Myself more than husband & $26[32.10]$ & 75 & 18 [17.65] & 51 & $22[18.80]$ & 63 & 66 [22.22] & 189 \\
\hline Both & $26[32.10]$ & 56 & $32[31.37]$ & 68 & 38 [32.48] & 79 & $96[32.00]$ & 203 \\
\hline $\begin{array}{l}\text { Husband/Family member more } \\
\text { than myself }\end{array}$ & $5[6.17]$ & 8 & $6[5.88]$ & 10 & 26 [22.22] & 39 & 37 [12.33] & 57 \\
\hline Husband/Family members & 18 [22.22] & 14 & $25[24.51]$ & 19 & 19 [16.24] & 14 & 62 [20.67] & 47 \\
\hline Total & $81[100]$ & 176 & $102[100]$ & 221 & $117[100]$ & 237 & $300[100]$ & 634 \\
\hline
\end{tabular}

Source: Survey data.

Note: Figures in brackets are percentage to the total. 
Citation: Narayanan S (2016) Analysis of Empowerment through Decision Making of Women in Madurai District of Tamil Nadu - A Study. Intel Prop Rights. 4: 161. doi: 10.4172/2375-4516.1000161

Page 4 of 5

of manufacturing sector and trading sector respectively. Thus, it is observed on the basis of total score value that working women decide the leisure activity in all the three sectors.

\section{Purchase of Home Appliances}

Purchase of home appliances is also an important variable or determinant for measuring empowerment. The details of decision making on purchase of home appliances are furnished in Table 5.

From the Table 5 it is learnt that 7.41 per cent in manufacturing, 8.82 per cent in service sector and 28.21 per cent of trading sector were in a position to purchase home appliances on their own decisions. Joint decision was taken by, 45.68 per cent in manufacturing sector, 25.49 per cent in service sector and 20.51 per cent in trading sector activity. Husband/family members' decision making relating to home appliances was 6.17 per cent and 14.53 per cent in manufacturing sector and trading sector respectively. It is inferred from the analysis that majority of the respondents take decisions independently regarding the purchase of home appliances in trading sector.

\section{Giving Away Gifts}

Transferring of gifts is a pleasure in human life. Gifts are given and received during some festivals and on special occasions in our life time.
We as members of society, have to give gifts to others on the occasions such as wedding, birth day, and the like. It is a well-known fact that the give and take policy enriches the friendship, harmony, mutual understanding, helpfulness and the like amongst the people. In the past, women did not have a say in presenting gifts to others; only male members took decisions in giving away the gifts. But, at present owing to Micro-Finance women have freedom and economic independence and so take decision independently or influence the other members in taking a decision in this regard. Table 6 presents some interesting results of decision making on giving away gifts to others (Table 6).

Table 6 clearly reveals that 6.17 per cent in manufacturing sector, 14.71 in service sector, and 20.51 per cent in trading sector make their own decision in giving gifts to others. 38.27 per cent and 13.68 per cent of the respondents in manufacturing sector and trading sector reported that they took decision jointly. It is observed during the survey that many women have said that if they had money, they could buy gifts for others.

\section{Personal Needs}

The details of decision making on personal needs of women are presented in Table 7.

It has been inferred from the Table 7 that, 6.17 per cent in

\begin{tabular}{|c|c|c|c|c|c|c|c|c|}
\hline \multirow[t]{2}{*}{ Final decision Taken } & \multicolumn{2}{|c|}{ Manufacturing Sector } & \multicolumn{2}{|c|}{ Service Sector } & \multicolumn{2}{|c|}{ Trading Sector } & \multicolumn{2}{|c|}{ Overall Total Score } \\
\hline & No. of Res. & Score & No. of Res. & Score & No. of Res. & Score & No. of Res. & Score \\
\hline Self & $6[7.41]$ & 24 & $9[8.82]$ & 33 & $33[28.21]$ & 118 & $48[16.0]$ & 175 \\
\hline Myself more than husband & 7 [8.64] & 24 & 16 [15.69] & 45 & $7[5.98]$ & 17 & 30 [10.0] & 86 \\
\hline Both & $37[45.68]$ & 77 & 26 [25.49] & 56 & $24[20.51]$ & 49 & 87 [29.0] & 182 \\
\hline $\begin{array}{l}\text { Husband/Family member more } \\
\text { than myself }\end{array}$ & $26[32.10]$ & 38 & 33 [32.35] & 48 & $36[30.77]$ & 49 & $95[31.67]$ & 135 \\
\hline Husband/Family members & $5[6.17]$ & 5 & $18[17.65]$ & 14 & $17[14.53]$ & 15 & 40 [13.33] & 34 \\
\hline Total & $81[100]$ & 168 & $102[100]$ & 196 & $117[100]$ & 248 & $300[100]$ & 612 \\
\hline
\end{tabular}

Source: Survey data.

Note: Figures in brackets are percentage to the total.

Table 5: Decision making on purchase of home appliances.

\begin{tabular}{|c|c|c|c|c|c|c|c|c|}
\hline \multirow[t]{2}{*}{ Final decision Taken } & \multicolumn{2}{|c|}{ Manufacturing Sector } & \multicolumn{2}{|c|}{ Service Sector } & \multicolumn{2}{|c|}{ Trading Sector } & \multicolumn{2}{|c|}{ Overall Total Score } \\
\hline & No. of Res. & Score & No. of Res. & Score & No. of Res. & Score & No. of Res. & Score \\
\hline Self & $5[6.17]$ & 17 & $15[14.71]$ & 53 & $24[20.51]$ & 82 & $44[14.67]$ & 152 \\
\hline Myself more than husband & 19 [23.46] & 54 & 21 [20.59] & 58 & $31[26.50]$ & 86 & 71 [23.67] & 198 \\
\hline Both & $31[38.27]$ & 65 & 31 [30.39] & 65 & 16 [13.68] & 35 & 78 [26.00] & 165 \\
\hline $\begin{array}{l}\text { Husband/Family member more } \\
\text { than myself }\end{array}$ & $22[27.16]$ & 32 & $28[27.45]$ & 40 & $14[11.97]$ & 20 & 64 [21.33] & 92 \\
\hline Husband/Family members & $4[4.94]$ & 5 & $7[6.86]$ & 8 & $32[27.34]$ & 25 & $43[14.33]$ & 38 \\
\hline Total & $81[100]$ & 173 & $102[100]$ & 224 & 117 [100] & 248 & 300 [100] & 645 \\
\hline
\end{tabular}

Source: Survey data.

Note: Figures in brackets are percentage to the total.

Table 6: Decision making on giving away gifts to others.

\begin{tabular}{|c|c|c|c|c|c|c|c|c|}
\hline \multirow[t]{2}{*}{ Final decision Taken } & \multicolumn{2}{|c|}{ Manufacturing Sector } & \multicolumn{2}{|c|}{ Service Sector } & \multicolumn{2}{|c|}{ Trading Sector } & \multicolumn{2}{|c|}{ Overall Total Score } \\
\hline & No. of Res. & Score & No. of Res. & Score & No. of Res. & Score & No. of Res. & Score \\
\hline Self & $5[6.17]$ & 17 & $6[5.88]$ & 22 & $22[18.81]$ & 77 & $33[11.00]$ & 116 \\
\hline Myself more than husband & 17 [20.99] & 47 & 16 [15.69] & 46 & 7 [5.98] & 18 & 40 [13.33] & 111 \\
\hline Both & $33[40.74]$ & 69 & $46[45.10]$ & 97 & $36[30.77]$ & 75 & 115 [38.33] & 241 \\
\hline $\begin{array}{l}\text { Husband/Family member more } \\
\text { than myself }\end{array}$ & $22[27.16]$ & 32 & 19 [18.63] & 28 & 26 [22.22] & 38 & 67 [22.34] & 98 \\
\hline Husband/Family members & $4[4.94]$ & 6 & $15[14.70]$ & 11 & 26 [22.22] & 21 & $45[15.00]$ & 38 \\
\hline Total & $81[100]$ & 171 & $102[100]$ & 204 & $117[100]$ & 229 & $300[100]$ & 628 \\
\hline
\end{tabular}

Source: Survey data.

Note: Figures in brackets are percentage to the total. 
manufacturing sector, 5.88 per cent in service sector and 18.81 per cent in trading sector take decision independently regarding their personal needs. The percentage of score value was greater in trading sector when compared to other sectors activity. 40.74 per cent in manufacturing sector, 45.10 per cent in service sector and 30.77 per cent in trading sector took decision jointly. Only 4.94 in manufacturing, 14.70 per cent in service sector and 22.22 per cent in trading sector, the decision was taken by husband/family members. Thus, it may be inferred from the score value that the majority of the respondents take decision on personal needs independently. Thus, it may be proved that after joining self-help groups, respondents have gained much more empowerment at socio-economic levels and in decision making.

It has been found that majority of women take their own independent decision relating to family budget, education of their children, family's health and medicine, the leisure time activities and personal needs, irrespective of manufacturing sector, service sector and trading sectors in the study area. It has been further observed that joint decisions have been taken by the women respondents in consultation with their husband/Family members regarding the purchase of home appliances and the purchase of gifts to be given to others on special occasions concerned.

It has been further observed that regarding the level of women's empowerment in various sectors. In the case of manufacturing sector activity, out of 81 respondents, 47 (58.02 per cent) of them belong to high level group, 22 (27.16 per cent) fall under medium level and the remaining 12 (14.82 per cent) belong to low level. Out of 102 in service sector, 62 (60.78 per cent), 23 (22.55 per cent) and 17 (16.67 per cent) belong to high, medium and low level empowerment. In the case of trading sector, out of 80 respondents, 53 (45.30 per cent) of them fall under high level, 26 (22.22 per cent) come under the category of medium level and 38 (32.48 per cent) fall under low level.

Chi-Square test shows that the calculated chi-square value for age, education, family size, spouse employment and income of the respondents in manufacturing sector are greater than the table value of the chi-square value at 5 per cent level of significance. Hence, it may be observed that there exists a relationship between the factors and level of empowerment. As the calculated value of chi-square is less than the table value of chi-square at 5 per cent level in the case of caste and types of family, the caste and types of family have no influence on the level of empowerment of the women in the study area. It may be observed that there is a relationship between the level of empowerment and age, education, family size, spouse employment and income of the respondents.

\section{Suggestions}

Though, these groups have made a positive impact on SHG women, SHG members suffer from lack of motivation, backward and forward linkages, inadequacy of infrastructure, insufficient loan, inadequate provision of marketing, non-availability of inputs, lack of systematic monitoring and follow up activities etc., Thus there is need to evaluate the SHGs annually to assess the progress of different income and employment generating schemes.
All service for women in rural areas should be integrated and offered as a package programme. All services and programmers related to agriculture, education, health care, nutrition, family planning and vocational training must be directed towards improving women's earning, increasing their productivity and making economic activity.

It is need of the hour that the government should form a Regulatory Authority to oversee the functioning of the Self-Help Groups and find out the members who are not participating in the income generation activities, but lend the money at exorbitant rate of interest. Suitable action may be taken against them.

\section{Conclusion}

It has been found that majority of women take their own independent decision relating to family budget, education of their children, family's health and medicine, the leisure time activities and personal needs, irrespective of manufacturing sector, service sector and trading sectors in the study area. It has been further observed that joint decisions have been taken by the women respondents in consultation with their husband/Family members regarding the purchase of home appliances and the purchase of gifts to be given to others on special occasions concerned.

\section{References}

1. Robinson MS (1996) Addressing Some Key Question in Finance and Poverty Journal of International Development 8: 153-161.

2. Kaladhar K (1997) Micro Finance in India. Economic and Political Weekly, India.

3. Archana S (2004) Micro Finance for Women's Empowerment Kurukshetra, 52.

4. Adams DW, Von Pishke JD (1992) Micro Enterprise Credit Programs; déjà vu.World Development 20: 1-9.

5. Adams DW, Robert CV (1986) Rural Financial Markets in Low Income Countries; Recent Controversies and Lessons. World Development 14: 477-487.

6. Bell C (1990) Interactions between Institutional and Informal Credit Agencies in Rural India. The World Bak Economic Review 4: 297-378. 